\title{
Operacionalização e custos materiais de um projeto de extensão para escolares da rede pública
}

\author{
Andre Luiz Marçal Terreri*, Flávia Paganini*** \\ * Professor da disciplina de Saúde Coletiva da Universidade Estadual do Oeste do \\ Paraná, UNIOESTE \\ ** Professora da disciplina de Saúde Coletiva da Universidade Paranaense, \\ UNIPAR
}

\begin{abstract}
RESUMO
A extensão universitária, frente às demandas sociais e à recente conclusão dos levantamentos epidemiológicos SB Brasil, que apontaram para uma grande dívida social no âmbito da saúde bucal, torna-se uma alternativa colaborativa para o desenvolvimento social do local onde estiver atuando. $\mathrm{O}$ objetivo deste trabalho foi descrever os custos e operacionalização de ações coletivas (escovação, evidenciação do biofilme e fluorterapia) realizadas semanalmente em 400 escolares matriculados na Escola Municipal de Ensino Infantil e Fundamental Recanto Feliz, localizada no município de Francisco Beltrão, PR. A metodologia utilizada tem como referência uma estimativa de custos materiais para um ano (40 semanas do ano letivo escolar), por meio do desenvolvimento de um Programa de Extensão realizado pelo Curso de Odontologia da Universidade Paranaense. O custo material do projeto realizado ficou em torno de $\mathrm{R} \$ 16,00$ por criança/ano, incluindo nesta fase, a aquisição de material de uso permanente (porta escova coletivo e individual), que poderá ser reutilizado nos anos seguintes, tornando as ações de saúde bucal de mais baixo custo, chegando a $\mathrm{R} \$ 8,34$ por criança/ano.

Descritores: Saúde Bucal. Custo e Análise de Custo. Relações Comunidade-Instituição.
\end{abstract}




\section{INTRODUÇÃO}

A extensão entendida como prática acadêmica que interliga a universidade em suas atividades de ensino e de pesquisa, com as demandas da maioria da população, possibilita a formação cidadã do profissional e a credencia, cada vez mais, junto à sociedade como espaço privilegiado de produção do conhecimento significativo para a superação das desigualdades sociais existentes. É importante consolidar a prática da extensão, possibilitando a constante busca do equilíbrio entre as demandas socialmente exigidas e as inovações que surgem do ambiente científico acadêmico ${ }^{1}$.

No que tange à saúde, as universidades devem atuar de maneira coordenada e articulada com os órgãos públicos, agindo para que as conquistas consolidadas na constituição brasileira e nas leis orgânicas da saúde sejam efetivadas e contribuam para o desenvolvimento regional em que a universidade está inserida. Essa relação será obtida pela efetiva interação entre a formação dos profissionais de saúde, os serviços de saúde do SUS e as comunidades, constituindo uma importante estratégia para auxiliar a promoção das mudanças necessárias na formação acadêmica e que podem contribuir para uma sociedade mais justa e solidária. Tão importante quanto o desenvolvimento dos projetos de extensão em parceria com setores públicos é avaliação dos custos financeiros para implantação e operacionalização, assim como identificar os benefícios aos indivíduos, familiares e comunidade na qual estas ações de saúde são desenvolvidas. Na saúde pública do Brasil, se não houvesse uma disparidade entre a quantidade demandada de serviços de saúde e o montante financeiro fornecido pelos governos, ações de saúde poderiam ser implantadas sem relevar a relação custo/benefício.

Entretanto, a realidade é diferente, o que vemos são orçamentos limitados, e quando se opta por aplicar os recursos em uma atividade, o uso desse recurso em outra atividade é negado (custos de oportunidade). O conceito de custo de oportuni- dade pressupõe alternativas viáveis ao gestor de saúde, que opta por uma delas em detrimento das demais. Neste sentido, a decisão tomada deve ser a mais efetiva pois acarretará o sacrifício/ abandono de outras alternativas que não foram adotadas. Instala-se, invariavelmente, uma competição pelos recursos financeiros e é difícil determinar qual área deveria ser sacrificada em prol da racionalização ${ }^{2}$.

No que se refere à literatura nacional e internacional sobre custo de ações de saúde bucal, tal como a escovação supervisionada, essa foi considerada escassa pelo autor ${ }^{3}$ que comparou o custo-efetividade entre dois programas de escovação supervisionada em crianças de 05 anos. Um programa intitulado convencional e o outro modificado devido ao emprego da técnica de escovação vestíbulo-lingual. O autor levou em consideração os gastos diretos relativos aos recursos humanos e materiais, com base no valor da quantidade de horas-trabalhadas e no valor do consumo de unidades de escova, creme dental e evidenciador de placa bacteriana. A efetividade foi medida pelo número de lesões de cárie apurado ao longo do estudo (18 meses). O autor concluiu que o programa modificado custou cerca de $\mathrm{R} \$ 3,04$ por criança, resultando numa razão de custoefetividade marginal (incremental) de $\mathrm{R} \$ 35,50$ por lesão evitada, sendo cerca de $\mathrm{R} \$ 10,00$ por lesão evitada entre os meninos (grupo de maior risco) ${ }^{3}$. O custo-efetividade marginal (incremental) foi empregado para verificar o quanto os custos adicionais da técnica de escovação vestíbulo-lingual gerariam em benefício adicional (redução das lesões de cárie) quando aplicada. $\mathrm{O}$ termo "incremental" é comumente usado para denotar o custo e resultado adicionais de uma intervenção, em comparação a outra.

Num estudo de caso, cujo objetivo foi estimar o custo da fluoretação das águas de abastecimento público no Município de São Paulo (período de 1985-2003), os autores levantaram junto à Companhia de Saneamento Básico do Estado de São Paulo (SABESP) e empresas fornecedoras de equipamentos, o custo do produto 
químico e dos equipamentos necessários à incorporação do flúor à água de abastecimento. Para a análise dos custos, estes foram estratificados em quatro grupos: (a) custo de capital inicial de instalação; (b) custo dos produtos químicos; (c) custo de operacionalização do sistema; e (d) custo de controle dos teores de flúor. Os autores observaram, usando dados epidemiológicos relativos à carie dentária, anteriores e posteriores ao início da fluoretação, para a idade de 12 anos, uma redução de $73 \%$ na experiência de cárie dentária, sendo que em 1986 a média do índice CPO-D era de 6,47 e em 2002 foi de 1,75 . $O$ custo médio per capita/ano na Cidade de São Paulo foi de R \$ 0,08 (US\$ 0,03) em 2003. O custo acumulado em 18 anos de implantação do sistema de fluoretação foi de $\mathrm{R} \$ 1,44$ (US\$ 0,97) per capita. O estudo mostrou que a fluoretação das águas é uma ação de alta eficiência, baixo custo relativo e grande benefício social ${ }^{4}$.

Em um estudo ${ }^{5}$ que avaliou os custos de implantação e operação da assistência odontológica no serviço público de saúde em um centro de especialidades de saúde bucal do Município de Sabará, Minas Gerais, os autores concluíram que as intervenções preventivo-promocionais realizadas por profissional de saúde em ambiente clínico representaram o segundo maior custo anual, ultrapassando os custos de especialidades como prótese e endodontia. Estes resultados sugerem que estas intervenções não deveriam ser recomendadas quando realizadas no ambiente clínico, devendo ser substituídas por ações populacionais amplas de menor custo.

A análise de custos de atividades preventivas e sua operacionalização no âmbito de escolas e creches públicas é relevante, pois são espaços adequados para realização desses procedimentos devido à presença constante das crianças em pelo menos um turno. O objetivo do presente estudo é apresentar os custos materiais e operacionalização de um projeto de extensão em saúde bucal do Curso de Odontologia de Francisco Beltrão, realizado por meio de parceria entre Universidade, Secretaria de Educação e Saúde. O projeto descrito pode oferecer uma previsão orçamentária e subsidiar tecnicamente instituições de ensino odontológico que queiram implantar este tipo de ação, considerando as limitações das peculiaridades existentes em cada localidade.

\section{METODOLOGIA}

Este estudo foi de abordagem quantitativa, com o objetivo de descrever a operacionalização e custos de um projeto de extensão em saúde bucal executado por acadêmicos da Universidade Paranaense (UNIPAR), para 400 crianças. Foi utilizada como técnica de pesquisa o estudo de campo, realizado na Escola Municipal Recanto Feliz, em Francisco Beltrão, PR. O levantamento dos custos e sua operacionalização estão relacionados ao desenvolvimento das seguintes atividades coletivas: escovação supervisionada direta; evidenciação do biofilme e a fluorterapia para as crianças com maior risco de cárie. Conforme já mencionado trata-se de um projeto de extensão universitária e não pesquisa envolvendo seres humanos. Dessa forma, o projeto pôde ser executado após parecer do Comitê de Ética informando que não haveria necessidade de avaliação (Conforme Resolução 466/12). Contudo, salientamos que os procedimentos asseguraram a confidencialidade, a privacidade, a proteção da imagem e a não estigmatização, garantindo a não utilização das informações em prejuízo das pessoas e/ou comunidade, inclusive em termos de autoestima, de prestígio econômico e/ou financeiro.

O projeto de saúde bucal é desenvolvido semanalmente, por meio da parceria entre a UNIPAR, Secretaria de Educação e Secretaria de Saúde de Francisco Beltrão. Na figura 1 é possível visualizar a forma de operacionalização do projeto de extensão.

O projeto é realizado semanalmente pelos estudantes do primeiro ano do curso de Odontologia, os quais desenvolvem atividades coletivas de saúde bucal para uma média de 800 crianças matriculadas, desde a pré-escola até o quarto ano desta instituição de ensino. Os escola- 


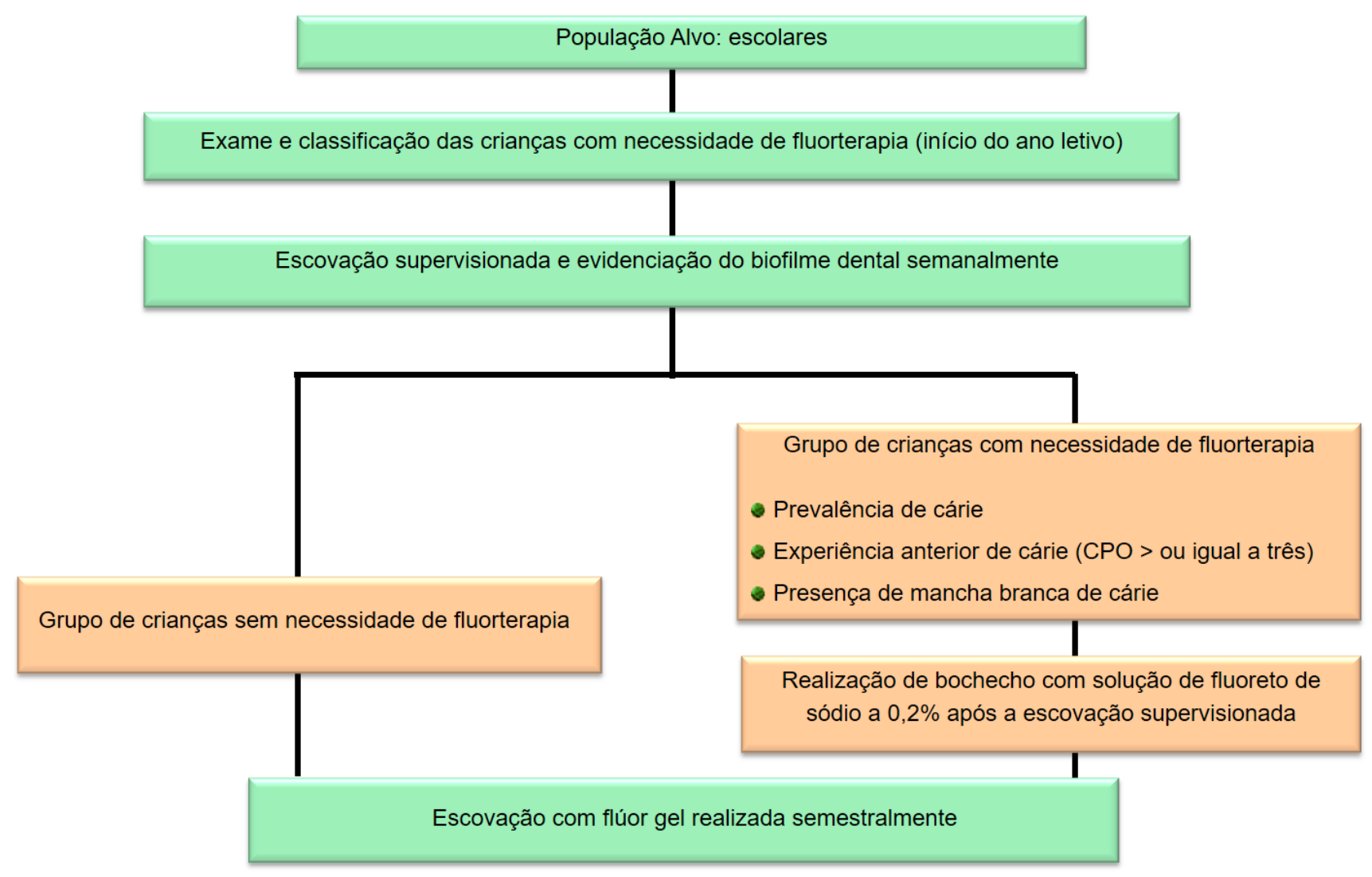

Figura 1 - Fluxograma de operacionalização do programa de extensão em saúde bucal desenvolvido.

lares estão distribuídos em 36 turmas, 18 matutinas e 18 vespertinas, com média de 22,3 alunos por turma.

O projeto é realizado semanalmente pelos alunos do primeiro ano do curso de odontologia, os quais desenvolvem atividades coletivas de saúde bucal para uma média de 800 crianças matriculadas, desde a pré-escola até o quarto ano desta instituição de ensino. Estes escolares estão distribuídos em 36 turmas, sendo 18 matutinas e 18 vespertinas, com uma média de entre 22,3 alunos por turma.

A totalidade dos alunos não foi utilizada como amostra, pois haveria crianças que não estariam presentes nos dias em que a contabilidade estava sendo realizada. Portanto, os gastos com o desenvolvimento das atividades coletivas foram estimados sempre tomando como referência a contabilização 400 crianças e tendo como parâmetro o ano letivo escolar, que possui 40 semanas. Durante quatro semanas consecutivas os pesquisadores acompanharam os gastos com os materiais de consumo e permanente, que seriam utilizados no ano letivo, entre eles: suporte para porta escovas individuais (comportam até 36 escovas por base); porta escovas individuais (Oralls® Parque Tecnológico, São José dos Campos, São Paulo, Brasil), escova dental (Medfio® Medfio Indústria e Comércio Artigos Odontológicos, Pinhais, Paraná, Brasil), dentifrício fluoretado (CloseUp Liquifresh ${ }^{\circledR}$ Unilever, São Paulo, São Paulo, Brasil), solução evidenciadora de biofilme (Eviplac® Biodinâmica Química e Farmacêutica LTDA, Ibiporã, Paraná, 
Brasil), micro aplicador descartável (KG brush® KG Sorensen, Cotia, São Paulo, Brasil), solução de fluoreto de sódio a 0,2\% (Fluorsul@ Iodontosul, Porto Alegre, Rio Grande do Sul, Brasil), flúor fosfato acidulado 2,0\% em gel (DFL® Nova DFL, Rio de Janeiro, Rio de Janeiro, Brasil) e abaixadores de língua (Estilo® Estilo Artefatos de madeira Ltda. Guarapuava, Paraná, Brasil).

No início do ano letivo uma lista com o nome dos alunos matriculados por sala foi solicitada e fornecida pela secretaria da escola com o objetivo de identificar os suportes (sala a que pertencia), os porta escovas individuais e as escovas (com o nome dos alunos) e distribuídos em conformidade com o número de salas e alunos envolvidos no programa.

A identificação foi feita com caneta marca plástico na cor preta. Após a organização dos kits de higiene bucal e distribuição nas salas de aula, o projeto tem início já no ambiente escolar, com a divisão dos alunos do curso de odontologia em monitores, examinadores, os supervisores da escovação e os responsáveis pela fluorterapia.

Esta atividade de extensão envolve 80 alunos do curso de odontologia, que são divididos em 4 turmas de 20 alunos, sendo que 2 turmas (uma antes do intervalo e a outra após) desenvolvem as atividades pela manhã e as outras 2 turmas no período da tarde, também em horários em conformidade com o horário de intervalo da merenda.

Em cada turma, uma média de seis alunos trabalhando em duplas ficam responsáveis pelas monitorias e desempenham a seguinte função; buscar as crianças em sala de aula, distribuir as escovas, organizar as filas dos exames e evidenciação, encaminhar para a escovação, fluorterapia, reorganizar a fila dos que já realizaram as atividades e retornar com as crianças para sala de aula. No início do ano letivo escolar e do projeto de extensão são identificadas as crianças com necessidade de fluorterapia considerando cavidades de cárie não tratadas, e/ou história passada de cárie (3 ou mais restaurações) e/ou presença de mancha branca de cárie visua- lizada sem a necessidade de secagem dos dentes, para que seu porta escova possa receber uma identificação da necessidade de fluorterapia.

Esta identificação é realizada com uma fita adesiva enrolada na parte externa do porta escova. Neste momento as crianças têm seus dentes evidenciados com solução evidenciadora à base de fucsina, com auxílio de um micro aplicador.

Para o controle da quantidade de solução usada para realização da evidenciação em 400 crianças, os pesquisadores, em laboratório, utilizaram uma pipeta milimetrada e com auxílio de um conta gotas verificaram que cada $\mathrm{ml}$ da solução correspondia a 20 gotas. Cada examinador recebia em seu pote dapen cinco gotas por meio do conta gotas (utilizado na medição supracitada) e a solução era aplicada com auxílio do micro aplicador de tamanho regular, suficiente para espalhar a solução na face vestibular de todos os dentes dos sextantes anteriores (média de 12 dentes).

Quando a solução do pote dapen era totalmente utilizada pelo examinador, cinco gotas eram repostas até que 400 evidenciações fossem realizadas e, assim, se pudesse verificar, em milímetros, a quantidade utilizada nesta amostra. Após a evidenciação do biofilme, oito acadêmicos ficavam responsáveis pela supervisão da escovação, realizada de maneira individual.

Os acadêmicos responsáveis pela escovação utilizaram 4 tubos de dentifrício gel novos que foram pesados em laboratório antes da sua utilização e novamente pesados após serem utilizados na escovação de 400 crianças. Dessa forma foi possível calcular, em média, a quantidade em gramas de dentifrício que foi utilizada em cada escovação.

Após a realização da escovação supervisionada, as crianças identificadas pelos examinadores e marcadas no seu porta escova com uma fita adesiva com necessidade de fluorterapia, eram encaminhadas para a realização do bochecho com solução de fluoreto de sódio a $0,2 \%$. Nas quatrocentas crianças que fizeram parte da estimativa de custos do projeto, foi possível identi- 
ficar uma média de 269 crianças que necessitavam de realizar o bochecho fluoretado além da escovação.

A técnica de aplicação da solução foi realizada com o auxílio de uma almotolia graduada, sendo a solução dispensada diretamente na boca da criança e bochechada durante um minuto. Para o controle do gasto de solução de fluoreto nesta ação, dois acadêmicos recebiam as almotolias com $200 \mathrm{ml}$ e utilizavam a solução até o fim, quando novamente eram preenchidas, pelos pesquisadores, até a marca dos $200 \mathrm{ml}$, sendo que, ao fim do bochecho das 269 crianças, foi possível estabelecer a quantidade em mililitros da solução aplicada.

Como parte da operacionalização do projeto, duas aplicações de flúor gel (uma por semestre) utilizando a escova dentária acontecem antes das férias escolares de julho e dezembro. Neste caso, foi utilizada a aplicação realizada em junho, sendo que três tubos de flúor fosfato gel acidulado 1,23\% foram pesados antes da aplicação e pesados novamente após utilizados em 400 crianças, sendo possível obter a média utilizada por criança/aplicação.

\section{RESULTADOS}

Para definir uma estimativa de custos, os pesquisadores consideraram a atividade sendo desenvolvida para 400 crianças em um calendário escolar com 200 dias letivos no ano, já que, as atividades de extensão do Curso de Odontologia são desenvolvidas semanalmente. Ajustado para fins de cálculos do custo material de consumo no ano, o calendário previa 40 semanas com atividades coletivas de saúde bucal. No início do projeto, para determinar a necessidade de fluorterapia (bochechos fluoretados), foram utilizados abaixadores de língua para cada exame realizado, totalizando quatrocentas unidades. Durante o ano letivo, para os 400 alunos seriam realizadas 15.200 evidenciações de biofilme e escovação supervisionadas, pois estas atividades são desenvolvidas semanalmente independentemente do risco de cárie. Este número é estimado pela multiplicação dos 400 alunos e as 38 vezes em que estas duas ações acontecem no ano, já que, na semana que antecede as férias (meio e fim do ano), apenas a aplicação tópica do flúor gel com a escova dentária é realizada. Em se tratando das aplicações do flúor gel, durante o ano letivo seriam realizadas 800 aplicações (duas por criança). Os bochechos fluorados foram realizados semanalmente em $67,2 \%$ (269) das crianças que apresentavam as características de maior risco de cárie e, multiplicando o número de bochechos pelas 38 semanas (excluídas as semanas de aplicação do flúor gel), teríamos 10.222 bochechos realizados no ano letivo. $\mathrm{Na}$ tabela 1 são apresentadas as quantidades utilizadas dos produtos comerciais de consumo, previstas para 40 semanas.

A troca das escovas dentárias não foi considerada necessária para as quatrocentas crianças que participaram da estimativa dos gastos, considerando-se quarenta o número de vezes em que as escovas dentárias seriam utilizadas, quantidade não suficiente para deformar as cerdas.

Considerando o produto comercial utilizado (consumo e permanente), o número de procedimentos realizados, a quantidade dos produtos utilizada, o período de um ano letivo e o número de crianças (400) que serviram como estimativa. Na tabela 2 são apresentados os gastos com o desenvolvimento do projeto de extensão.

O valor de $\mathrm{R} \$ 6.398,84$ reais gastos inicialmente com a implantação do projeto pode ser reduzido, mantendo-se as mesmas atividades, se considerarmos que o 18 suportes e os 400 porta escovas individuais constituem-se como recurso permanente. Estes materiais são confeccionados com material termoplástico que permite sua desinfecção química e reutilização nos anos seguintes, aspectos que serão apresentados e discutidos adiante. 
Tabela 1 - Produtos comerciais utilizados no projeto de extensão para escolares e quantidade utilizada conforme sua forma comercial.

\begin{tabular}{lcc}
\hline \multicolumn{1}{c}{ Material de consumo } & $\begin{array}{c}\text { Quantidade } \\
\text { utilizada }\end{array}$ & Quantidade na forma comercializada \\
\hline Suporte com porta escovas individuais & 18 unidades & 18 suportes com 400 porta escovas \\
Escovas dentárias & 400 unidades & 400 unidades \\
Solução evidenciadora & $243,2 \mathrm{ml}$ & 25 frascos de $10 \mathrm{ml}$ \\
Micro aplicador & 15200 unidades & 152 potes com $100 \mathrm{un}$. \\
Abaixador de língua & 400 unidades & 4 pacotes com $100 \mathrm{un}$ \\
Dentifrício & $2736 \mathrm{~g}$ & 28 tubos de $100 \mathrm{~g}$ \\
Fluoreto de sódio 0,2\% & $63376 \mathrm{ml}$ & 64 litros \\
Flúor fosfato gel acidulado & $284 \mathrm{~g}$ & 2 frascos de $208 \mathrm{~g}$ \\
\hline
\end{tabular}

Tabela 2 - Produtos comerciais utilizados no projeto de extensão para escolares e respectivos preços e gastos por ano e criança

\begin{tabular}{|c|c|c|c|c|}
\hline Produto comercial & $\begin{array}{l}\text { Quantidade do produto na } \\
\text { forma comercializada }\end{array}$ & $\begin{array}{c}\text { Preço } \\
\text { unitário em } \\
\text { reais }\end{array}$ & $\begin{array}{l}\text { Valor total } \\
\text { em reais } \\
\text { ano }\end{array}$ & $\begin{array}{c}\text { Valor por } \\
\text { criança/ano } \\
\text { em reais }\end{array}$ \\
\hline Suporte com porta escovas individuais & 18 unidades & 170,00 & $3.060,00$ & 7,65 \\
\hline Escovas dentárias & 400 unidades & 0,80 & 320,00 & 0,80 \\
\hline Solução evidenciadora & 25 frascos de $10 \mathrm{ml}$ & 8,90 & 222,50 & 0,55 \\
\hline Micro aplicador & 152 potes com 100 unidades & 11,90 & $1.808,80$ & 4,52 \\
\hline Abaixador de língua & 4 pacotes com 100 unidades & 4,90 & 19,60 & 0,04 \\
\hline Dentifrício & 28 tubos de $100 \mathrm{~g}$ & 4,60 & 128,80 & 0,32 \\
\hline Fluoreto de sódio $0,2 \%$ & 64 litros & 12,95 & 828,80 & 2,07 \\
\hline Flúor fosfato gel acidulado & 2 frascos de $208 \mathrm{~g}$ & 5,17 & 10,34 & 0,02 \\
\hline Estimativa do valor total & & & $6.398,84$ & 15,99 \\
\hline
\end{tabular}

\section{DISCUSSÃO}

Trata-se de um projeto de extensão de uma instituição de ensino privada, em parceria com o setor público de saúde e educação, com o objetivo de fortalecer a integralidade das ações em saúde, contribuindo para superar a fragmentação das atividades no interior das unidades de saúde, já que a saúde bucal deve estar articulada com outras ações intra e intersetoriais. Serve ainda como oportunidade para o aprendizado dos acadêmicos sobre o planejamento e execução de atividades educativo-preventivas, que complementam sua vivência técnico-profissional e despertam a sensibilidade social, tão necessária à sua formação acadêmica ${ }^{6}$. Vale lembrar que o projeto de extensão está em fina sintonia com o Programa
Saúde na Escola (PSE), vigente no país, que contribui para a construção de sistema de atenção social, com foco na promoção da cidadania e nos direitos humanos, de forma a fortalecer $o$ enfrentamento das vulnerabilidades no campo da saúde e que comprometem o desenvolvimento escolar ${ }^{7}$.

Os gastos para a implantação e execução do projeto de extensão foram custeados pelos acadêmicos, como forma de "trote solidário", o que resultou em viabilização imediata aliada à possibilidade da continuidade do projeto de extensão para os anos seguintes, por meio das turmas ingressantes. A possibilidade de custeamento dos recursos materiais que seriam utilizados no projeto de extensão foi discutida após 
reuniões com gestores da Secretaria de Saúde e Educação. Entretanto a demora na licitação para compra dos produtos e a impossibilidade de adquirir todos os materiais de consumo necessários para o desenvolvimento do projeto na íntegra foram contratempos para o início do projeto de extensão. Nesta primeira etapa de implantação do projeto, cada acadêmico ingressante, num total de oitenta, desembolsou uma quantia de oitenta reais para aquisição de materiais permanentes e de consumo, tendo como parâmetro 400 crianças que seriam cobertas pelo projeto. Isto fez com que os gastos por criança neste ano ficassem em torno de dezesseis reais, conforme tabela 2.

Este custo inicial, principalmente devido à aquisição do suporte coletivo e o porta escova individual, é bastante elevado quando consideramos o repasse per capita, realizado pelo governo federal, do piso de Atenção Básica Fixo, que varia de vinte e três reais a vinte e oito reais habitante ao ano. Contudo, sua continuidade e a simplificação na sua operacionalização podem reduzir os gastos de forma significativa, conforme explanação seguinte.

Os idealizadores do projeto consideram o suporte coletivo e o porta escova individual como materiais de uso permanente, pois são passíveis de desinfecção química e reutilização nos anos posteriores, sendo descartada somente a escova utilizada no projeto. Assim, mantido o número de escolares no consecutivo, o custo para cada acadêmico ficará em torno de quarenta e dois reais e os custos por criança ano é reduzido para oito reais e trinta quatro centavos.

Se considerássemos somente a escovação supervisionada como única atividade a ser desenvolvida no âmbito escolar, por ser a mais importante na redução da doença cárie, devido ao uso do dentifrício fluoretado, esta atividade teria um custo material anual de oito reais e setenta e sete centavos, e quando reutilizado o suporte coletivo e o porta escova individual, o custo anual por criança sairia por um real e doze centavos.

É importante frisar que a progressão das lesões cariosas na fase escolar, o surgimento da dor e infecção, podem resultar em complicações locais, sistêmicas, psicológicas e sociais ${ }^{8}$, aspectos que na fase escolar podem traduzir em consequências no aprendizado, perda de aula devido a consultas, dificuldades de socialização com outras crianças, trazendo consequências negativas, tais como inferiorização e angústias.

A fluorterapia, por meio do bochecho fluoretado, é uma das atividades que compõem a operacionalização do projeto que, diferentemente da escovação supervisionada, realizada para todas as crianças independentemente do risco de cárie, adota critérios de risco para sua aplicação.

O município de Francisco Beltrão possui sistema de fluoretação das águas de abastecimento público. Quando isto ocorre é sempre importante considerar a associação dos métodos tópicos, tais como o bochecho, em conjunto com o uso regular de dentifrício fluoretado 9 , pois, pouco efeito adicional na redução da doença cárie tem sido observado $^{10}$, o que acarretaria um custo desnecessário.

Entretanto, Francisco Beltrão participou da amostragem do levantamento epidemiológico Brasil SB 2010 ${ }^{11}$, cujos resultados mostraram que crianças de 5 anos de idade apresentavam uma condição dentária pior que a média nacional no ano do levantamento, com ceo-d 3,75 aos cinco anos e CPO-D de 2,71 aos 12 anos, sendo o componente cariado responsável por mais de $70 \%$ da composição do índice na dentição decídua.

O projeto é desenvolvido em um modelo no qual o caráter programático das ações e a epidemiologia ocupam papel central na racionalização dos recursos existentes, principalmente referente à fluoterapia, visando à melhor relação de custo-efetividade, oferecendo mais ações a quem mais necessita, com base em critério de risco. O planejamento das ações de fluorterapia (bochechos fluorados semanais) foi determinado por meio de triagem de risco para todos os alunos, identificados em seu porta escova individual.

A escovação supervisionada foi realizada independente do risco de cárie. A triagem realiza- 
da pelos alunos, supervisionada pelos docentes, tem permitido aos acadêmicos do curso desenvolverem um olhar de identificação e vigilância sobre os sinais de risco em saúde bucal, tais como: presença de manchas e cavidades nos dentes, bem como sua coloração; presença de placa, alterações gengivais e sangramento devido à falta de escovação diária.

O projeto possui como limitação a avaliação apenas do risco de cárie considerando os determinantes biológicos/odontológicos do processo saúde-doença, sendo que não é possível identificar o risco familiar (identificado durante as visitas familiares, no que se refere à forma de organização, hábitos comportamentais e culturais e relações sociais estabelecidas pelas famílias) no ambiente escolar. Entretanto, a Escola Municipal Recanto Feliz é atualmente a instituição de ensino pública municipal com o maior número de alunos matriculados e localizada no bairro Pinheirão.

Uma pesquisa $^{12}$ desenvolvida com o objetivo de realizar uma avaliação espacial da qualidade de vida na cidade de Francisco Beltrão, a partir de uma análise sistêmica, envolvendo dez parâmetros selecionados por meio de fundamentação teórica, mostrou que a qualidade de vida no bairro Pinheirão foi considerada de "ruim à péssima", tendo como fatores que mais contribuíram: a média de pessoas por domicílio, o percentual de pessoas em domicílios com esgoto na rede, os percentuais de pessoas alfabetizadas, as distâncias da área central da cidade, e a renda média das pessoas. A escolha deste espaço social para o desenvolvimento das atividades de extensão teve o objetivo de chamar a atenção dos acadêmicos para a necessidade de parcerias com o setor governamental e a sociedade civil, aprofundando valores como a cidadania, solidariedade, comprometimento e o humanismo $^{13}$.

A participação direta dos acadêmicos no desenvolvimento do projeto os auxilia no desenvolvimento de competências relacionadas ao planejamento, organização, supervisão e avaliação das atividades desenvolvidas, enfatizando que essas ações no serviço público devem ser realizadas, preferencialmente, pelo agente comunitário de saúde, técnico e auxiliar de saúde bucal e professores. Cabe aos cirurgiões-dentistas (CD) o papel de planejar com os diversos sujeitos, coordenar e supervisionar as atividades coletivas, não que seu papel deva ser centrado no atendimento individual, mas seus turnos extramuros devem ser utilizados de maneira resolutiva ${ }^{14}$.

É possível encontrar na literatura pesquisas ${ }^{15,16}$ que identificaram os $\mathrm{CD}$ restritos ao atendimento clínico ambulatorial básico (exodontias, evidenciação de placa, orientação da dieta, aplicação tópica de flúor, restaurações, orientação de higiene oral e procedimentos básicos de periodontia) e os Auxiliares em Saúde Bucal (ASB) centrados em atividades convencionais (instrumentação do CD, desinfecção e esterilização de materiais e instrumentais), sem priorização das ações coletivas (visitas domiciliares, ações de prevenção e promoção à saúde e realização de reuniões com a comunidade de abrangência).

Alguns estudos ${ }^{17,18,19}$ relatam que parte das atividades preventivas coletivas inseridas na Estratégia Saúde da Família são desenvolvidas para escolares no âmbito das escolas, dentre elas a educação em saúde bucal, aplicação tópica de fluoretos (bochechos e gel fluoretado) e escovação supervisionada. Entretanto palestras e aplicações tópicas de flúor não necessariamente precisariam ser feitas nas $\operatorname{escolas}^{18}$, principalmente em se tratando dos domicílios e unidades de saúde como pontos importantes na rede de atenção básica à saúde bucal ${ }^{13}$, contudo, as escolas e creches são espaços adequados para realização desse procedimento pela presença constante das crianças (pelo menos um turno/dia) ${ }^{20}$.

A Estratégia Saúde da Família (ESF) dispõe de uma importante ferramenta de atuação equânime, que é o cadastro das famílias, com visita aos domicílios de acordo com prioridade predefinida por microárea de risco. Entretanto, não é difícil imaginar que durante as visitas pela equipe 
de saúde bucal e agentes comunitários de saúde, muitas crianças não estarão presentes nos domicílios, por estarem nas escolas, e algumas delas permanecendo em horário integral.

Enfim, faz parte do conteúdo teórico deste projeto de extensão que tal prática não é um resquício do modelo de atenção à saúde bucal em escolares, surgido ainda nos anos 1950 e representado principalmente pelo Sistema Incremental, e que a priorização dessa população não significa excluir outras faixas etárias e fases da vida.

Este projeto desenvolvido no âmbito da escola ocorre no primeiro ano do curso de odontologia (disciplina de Saúde Bucal Coletiva I) e, no segundo ano, a disciplina Estágio Comunitário Multidisciplinar trabalha o núcleo familiar. De maneira semelhante ao projeto com os escolares, há parceria com Secretaria de Saúde de Francisco Beltrão, de forma que os acadêmicos desenvolvam atividades extramurais juntamente com as Equipes de Saúde da Família, tanto em âmbito ambulatorial como durante as visitas realizadas pelos agentes comunitários aos domicílios.

Outras atividades de extensão relacionadas com saúde bucal podem ser desenvolvidas no âmbito escolar, tais como educação de sujeitoschave para saúde (professores, agentes comunitários de saúde, merendeiras e pais de alunos); inserção da educação em saúde bucal nas atividades escolares formais; orientação, implantação ou adequação de espaços adequados (escovódromos) para realização de atividades coletivas em saúde bucal; disponibilização de insumos para higiene bucal (quando não disponibilizado pelas secretarias de saúde/educação) em quantidade e qualidade adequada; realização de levantamentos epidemiológicos com finalidade de auxiliar a equipe de saúde bucal da Unidade de Saúde em sua área de abrangência na organização da demanda e divulgação dos índices epidemiológicos para estimular o planejamento e avaliação das medidas realizadas.
A intersetorialidade é um requisito importante na construção do modelo de saúde bucal no município e envolve a articulação entre sujeitos de diferentes setores sociais (saúde e educação) no enfrentamento de problemas complexos, contudo, a ação intersetorial como processo organizado, não ocorre de forma espontânea, ou seja, depende de uma ação que a impulsione. Após três anos de desenvolvimento do projeto foi possível somente, mesmo que de forma ainda muito tímida, o envolvimento e colaboração de alguns professores em realizar a escovação supervisionada nas crianças que permanecem em período integral.

Ainda há resistência dos professores em realizar esta atividade para todas as crianças nos dias da semana em que o projeto de extensão não está acontecendo, contudo este ainda é um objetivo dos idealizadores do projeto. Os autores julgam que há necessidade de novas oficinas de capacitação junto aos professores, ampliando seus conhecimentos além da forma correta de realizar a escovação e sua importância na prevenção da cárie. Acreditamos na necessidade de conscientizar os professores da importância da saúde bucal e suas reciprocidades com outras doenças sistêmicas, não somente nesta fase da vida escolar, mas principalmente quando forem adultos e idosos.

No ensino superior uma mudança paradigmática na reprodução do modelo biomédico deve ser pretendida na formação profissional, pois em torno de $27 \%$ dos cirurgiõesdentistas brasileiros estão prestando algum tipo de atendimento no serviço público ${ }^{21}$. Essa mudança será obtida pela efetiva interação entre a formação dos profissionais de saúde, os serviços de saúde do SUS e as comunidades, constituindo uma importante estratégia para promover as mudanças necessárias na formação acadêmica. A educação do profissional também não pode se encerrar com a conclusão do curso, pois deve se manter numa continuidade durante toda sua vida. Assim, estudantes, professores, profissionais de saúde e usuários devem ser sujeitos dessa mudança, cons- 
tituindo o processo coletivo de reflexão crítica sobre as práticas tradicionais, de aquisição de novos conhecimentos ${ }^{22}$.

Por fim, os autores defendem que projetos de extensão universitária, quando operacionalizados de forma contínua, realizados por meio de parcerias intersetoriais (educação e saúde), podem contribuir para aumento da cobertura dos serviços de saúde. A participação direta dos acadêmicos na implantação e manutenção é importante para formação de habilidades e competências relativas ao desenvolvimento de ações preventivas e coletivas destinadas aos escolares.

\section{CONCLUSÕES}

O custo material do projeto realizado ficou em torno de 16,00 reais por criança/ano, incluindo, nesta fase, a aquisição de material de uso permanente (porta escova coletivo e individual), que poderá ser reutilizado nos anos seguintes, tornando as ações de saúde bucal do projeto de extensão de mais baixo custo, chegando a 8,34 reais criança/ano.

Se considerássemos somente a escovação supervisionada como única atividade a ser desenvolvida no âmbito escolar, por ser a mais importante na redução da doença cárie, devido ao uso do dentifrício fluoretado, esta atividade teria um custo material anual de oito reais e setenta e sete centavos, e quando reutilizado o suporte coletivo e o porta escova individual, o custo anual por criança sairia por um real e doze centavos.

Este levantamento de custos pode servir de parâmetro para que instituições de ensino possam desenvolver o projeto de extensão de forma parecida.

\section{ABSTRACT \\ Operationalization and financial costs of an extension program for students of public schools The university extension, concerning social demands and the recent results of SB Brazil epidemiological surveys, which pointed to a great social debt in the context of oral health, becomes a collaborative alternative to the social development}

of the place where it is acting. The aim of this study was to describe the costs and operationalization of collective actions (teeth brushing, plaque disclosure and fluortherapy) held weekly in 400 children enrolled at the Municipal School of infant and primary education Recanto Feliz, in the municipality of Francisco Beltrão, PR. The methodology used takes as reference an estimated cost of material for a year (40 weeks of the school year) by developing an Extension Program conducted by the Dentistry course of Universidade Paranaense. The project financial cost was around $\mathrm{R} \$ 16.00$ per child/year, including the acquisition of permanent use material (collective and individual brush holders), which can be reused in subsequent years, lowering the costs of oral health actions, reaching $\mathrm{R} \$ 8.34$ per child/year.

Descriptors: Oral Health. Cost-Benefit Analysis. Community-Institutional Relations

\section{REFERÊNCIAS}

1. Nogueira MDP. Políticas de extensão universitária. Belo Horizonte: Editora UFMG; 2005.

2. White BA. The costs and consequences of neglected medically necessary oral care. Spec Care Dentist 1995; 15;(5):180-6.

3. Frazão P. Custo-efetividade da escovação dental supervisionada convencional e modificada na prevenção da cárie em molares permanentes de crianças de 5 anos de idade. Cad Saúde Pública 2012; 28(2):281-90.

4. Frias AC, Narvai PC, Araújo ME, Zilbovicius C, Antunes JLF. Custo da fluoretação das águas de abastecimento público, estudo de caso Município de São Paulo, Brasil, período de 1985-2003. Cad Saúde Pública 2006; 22(6):1237-46.

5. Ferreira C, Loureiro CA. Custos para implantação e operação de serviço de saúde bucal na perspectiva do serviço e da sociedade. Cad Saúde Pública 2008; 24(9):2071-80.

6. Medeiros Junior A, Alves MSCF, Nunes JP, Costa ICC. Experiência extramural em hospi- 
tal público e a promoção da saúde bucal coletiva. Rev Saúde Pública 2005; 39(2):30510 .

7. Brasil. Decreto $n^{\circ}$. 6.286, de 5 de dezembro de 2007. Institui o Programa Saúde na EscolaPSE, e dá outras providências [internet]. Diário Oficial [da] República Federativa do Brasil. 2007. Acesso em: 09/jan/2016. Disponível em: http://www.planalto.gov.br/ ccivil_03/ato2007-2010/2007/decreto/d628 $\underline{6 . h t m}$

8. Losso EM, Tavares MCR, Silva JYB, Urban CA. Cárie precoce e severa na infância: uma abordagem integral. J Pediatr 2009; 85(4) :295-300.

9. Ministério da Saúde. Secretaria de Atenção à Saúde. Departamento de Atenção Básica. Guia para recomendações do uso de fluoretos no Brasil. Brasília; Ministério da Saúde; 2009.

10. Marinho VC, Higgins JP, Sheiham A, Logan S. Combinations of topical fluoride (toothpastes, mouthrinses, gels, varnishes) versus single topical fluoride for preventing dental caries in children and adolescents. Cochrane Database of Systemic Reviews 2004. Acesso em: 14/set/2016. Disponível em: http://onlinelibrary.wiley.com/wol1/doi/ 10.1002/14651858.CD002781.pub2/abstract

11. Ministério da Saúde. Projeto SB Brasil 2010: Pesquisa Nacional de Saúde Bucal resultados principais. Brasília: Ministério da Saúde; 2011.

12. Andres J. Qualidade de vida urbana em Francisco Beltrão (SW/PR) por meio de geoprocessamento e análise multicritério. Ciência e Natura 2015; 37(4):298-310.

13. Paraná. Secretaria de Estado da Saúde do Paraná. Superintendência de Assistência à Saúde. Linha guia de saúde bucal. Curitiba, 2014. 76p.

14. Manfredini M.A. PSF: promovendo saúde bucal. Rev Bras Saúde Fam 2004; 5(7):62-71.

15. Pereira CRS, Roncalli AG, Cangussu MCT, Noro LRA, Patrício AAR, Lima KC. Impacto da Estratégia Saúde da Família sobre indica- dores de saúde bucal: análise em municípios do Nordeste brasileiro com mais de 100 mil habitantes. Cad Saúde Pública 2012; 28(3) :449-62.

16. Baldani MH, Fadel CB, Possamai T,Queiroz MGS. A inclusão da odontologia no Programa Saúde da Família no Estado do Paraná, Brasil. Cad Saúde Pública 2005; 21(4):1026-35.

17. Almeida GCM, Ferreira MAF. Saúde bucal no contexto do Programa Saúde da Família: práticas de prevenção orientadas ao indivíduo e ao coletivo. Cad Saúde Pública 2008; 24(9) :213-40.

18. de Souza, TMS, Roncalli AG. Saúde bucal no Programa Saúde da Família: uma avaliação do modelo assistencial. Cad Saúde Pública 2007; 23(11):2727-39.

19. Chaves SCL, Viera-Da-Silva LM. Atenção à saúde bucal e a descentralização da saúde no Brasil: estudo de dois casos exemplares no Estado da Bahia. Cad Saúde Pública 2007; 23(5):1119-31.

20. dos Santos AM. Organização das ações em saúde bucal na estratégia de saúde da família: ações individuais e coletivas baseadas em dispositivos relacionais e instituintes. Rev APS, 2006; 9(2):190-200.

21. Morita MC, Haddad AE, Araújo ME. Perfil atual e tendências do cirurgião-dentista brasileiro. Maringá: Dental Press; 2010.

22. de Araujo ME. Palavras e silêncios na educação superior em odontologia. Ciênc Saúde Colet 2006; 11(1):179-82.

Correspondência para:

André Luiz Marçal Terreri

e-mail: andreterreri@hotmail.com

Rua Carlos Gomes, 2275

85810-100 Cascavel, PR 